\title{
A Preseason Training Program With the Nordic Hamstring Exercise Increases Eccentric Knee Flexor Strength and Fascicle Length in Professional Female Soccer Players
}

\author{
Karoline Baptista Vianna', Lívia Gonçalves Rodrigues', Nathalia Trevisol Oliveira', João Breno Ribeiro-Alvares', Bruno \\ Manfredini Baroni ${ }^{1}$ a \\ 1 Universidade Federal de Ciências da Saúde de Porto Alegre \\ Keywords: football, eccentric training, injury prevention, knee flexors \\ https://doi.org/10.26603/001c.19452
}

\section{International Journal of Sports Physical Therapy}

Vol. 16, Issue 2, 2021

\section{Background}

Training programs that include the Nordic hamstring exercise (NHE) have been shown to increase eccentric knee flexor strength and biceps femoris fascicle length in male athletes. However, the effect of NHE on female athletes remains unknown.

\section{Purpose}

To investigate the collective and individual responses of professional female soccer players engaged in a preseason training program with the NHE regarding eccentric knee flexor strength and biceps femoris long head fascicle length.

\section{Study Design}

Quasi-experimental study.

\section{Methods}

Sixteen amateur female soccer players (without a NHE training routine) were evaluated 8-weeks apart to: (1) assess reliability of eccentric knee flexor strength and biceps femoris fascicle length measures; and (2) determine the typical error of measures that would be used to discriminate training responders and non-responders. The NHE training group had 17 professional female soccer players who performed an 8-week training program with the NHE during preseason. Within-group analysis was performed with paired sample t-tests (pre- vs. post-training), and individual responses were determined using the typical error criteria.

\section{Results}

The non-trained group's data demonstrated that measures of strength (ICC $=0.82-0.87$, typical error $=12-13 \mathrm{~N})$ and fascicle length $(\mathrm{ICC}=0.92-0.97$; typical error $=0.19-0.38 \mathrm{~cm}$ ) were reliable. In the NHE training group, both limbs increased the eccentric knee flexor strength ( 13\%; ES=0.74-0.82) and the biceps femoris fascicle length ( $6 \%$; ES=0.44-0.65). Twelve players ( $71 \%$ ) were considered responders to the NHE training program for the eccentric knee flexor strength, while eight athletes ( $47 \%)$ were responders for the biceps femoris fascicle length.

\section{Conclusion}

The 8-week preseason training program with the NHE increased both eccentric knee

\footnotetext{
a Corresponding author: Bruno Manfredini Baroni;

Federal University of Health Sciences of Porto Alegre (UFCSPA);

Sarmento Leite St, 245 - zipcode 90050-170;

Porto Alegre, Rio Grande do Sul, Brazil;

Phone/fax +55 51 3303-8876;

Email:bmbaroni@yahoo.com.br
} 
flexor strength and biceps femoris fascicle length in professional female soccer players. More than two-thirds of players demonstrated a meaningful increase in eccentric strength, while nearly half achieved consistent fascicle length increases with the NHE training.

\section{INTRODUCTION}

Top-level male soccer players present injury rates of 4.1 / 1.000 hours of training exposure and 27.5/1.000 hours of match exposure, ${ }^{1}$ while injury rates in female players are 2.7-3.1/1.000 hours and 13.9-23.6/1.000 hours in training and matches, respectively. ${ }^{2-4}$ According data from 2016-2017 season, English Premier League male clubs suffered an average of 1410 days out due to injury and lost $£ 45$ million per season due to injury-related decrements in performance. ${ }^{5}$ The extent of the injury-related losses is not yet clear in the context of female professional soccer, but there is no doubt that injury prevention is a current priority of soccer medicine in both sexes.

Sport injuries are complex and multifactorial in nature, ${ }^{6}$ so the prevention strategies require a multidimensional approach, which includes specific exercises to enhance muscle strength, joint mobility, neuromuscular control, and movement efficiency, as well as other strategies (e.g., workload monitoring). ${ }^{7}$ Understanding of injury mechanisms and identification of potential risk factors play a key role on preventing strategies in sports. ${ }^{8}$ Therefore, soccer clubs apply a range of tests for screening intrinsic risk factors and employ specific strategies to minimize the injuries' incidence and/or burden. ${ }^{9,10}$

The hamstring strain injury is one of the most prevalent injuries in team sports, including soccer. ${ }^{11}$ Up to $80 \%$ of hamstring injuries in soccer occur during high speed running. ${ }^{12}$ While direct evidence is still lacking, the majority of the literature suggests that the most likely timing of injury is the late swing phase, characterized by peak musculotendon strain and negative work. ${ }^{13}$ Low eccentric knee flexor strength is traditionally pointed out as a risk factor for hamstring injuries, ${ }^{11}$ which have been supported by prospective studies with soccer players, ${ }^{12,14-16}$ as well as with athletes from other sports. ${ }^{17-19}$ More recently, a prospective study evidenced that players with short fascicles in the biceps femoris long head $\left(\mathrm{BF}_{\mathrm{LH}}\right)$ are also more likely to sustain hamstring injury. ${ }^{12}$ All these studies have only focused on outcomes for male athletes. ${ }^{12,14-19}$ However, it seems reasonable that prevention programs for both sexes should address strategies to increase the eccentric knee flexor strength and the $\mathrm{BF}_{\mathrm{LH}}$ fascicle length.

The Nordic hamstring exercise (NHE) is a field-based exercise with focus on eccentric action of knee flexor muscles. ${ }^{20}$ The NHE was included in the injury prevention program developed by the Fédération Internationale de Football Association (FIFA), the "FIFA 11+", 21 and has been consolidated as one of the commonly used strategies to prevent hamstring injuries in top-tier soccer clubs. ${ }^{9,10}$ A recent systematic review including male and female athletic populations supports that teams using injury prevention programs that included the NHE reduces hamstring injury rates by half. ${ }^{22}$ This preventive effect seems to be related to increases on both eccentric knee flexor strength and $\mathrm{BF}_{\mathrm{LH}}$ fascicle length. ${ }^{23-27}$ However, no study has evaluated whether
NHE promotes such muscular adaptations in female soccer players. Therefore, the aim of this study was to investigate the collective and individual responses of professional female soccer players engaged in a preseason training program with the NHE regarding eccentric knee flexor strength and $\mathrm{BF}_{\mathrm{LH}}$ fascicle length.

\section{METHODS}

\section{STUDY DESIGN}

A group of amateur female soccer players (without a NHE training routine) was recruited and evaluated twice within an 8-week interval. These data were used to: (1) assess the reliability of measures collected in this trial; and (2) determine the typical error of measures that would be used to discriminate responders and non-responders in the NHE training group.

In the NHE training group, professional female soccer players completed an eight-week NHE training program coinciding with the club preseason. The participants' randomization into experimental and control groups was not possible due to the club requirement that all players should perform the preventive program using the NHE. Evaluations were performed one week before starting and one week after ending the training program.

The Ethics Committee of the Federal University of Health Sciences of Porto Alegre (Porto Alegre, Brazil) approved the present study. All subjects were informed about the study purpose and procedures, and provided written informed consent to participate.

\section{PARTICIPANTS}

Sixteen amateur female soccer players were part of the nontrained group. They were recruited through the dissemination of the study on social media and played soccer at least once a week. The NHE training group had 17 professional female soccer players from a Brazilian first national division team. They were engaged in a five-day weekly training routine, and one to two weekly games per week. Characteristics of participants are expressed in Table 1.

The following inclusion criteria were adopted: (1) age between 18 and 40 years of age; (2) absence of thigh muscle injuries in the six months prior to the study; (3) absence of musculoskeletal injuries in lower limbs during data collection; (4) absence of any health disorders that would interfere with the NHE execution. Participants allocated in the NHE training group had to have attended a minimum of 14 training sessions (i.e., $90 \%$ adherence) to be included in data analysis, while participants allocated in the nontrained group should have kept their usual exercise routine between the two evaluation time-points. All participants were instructed not to consume any stimulant substance, medicine or alcoholic beverages in the 24 hours before the testing sessions. 
Table 1: Characteristics of participants (mean \pm SD).

\begin{tabular}{lcc}
\hline & $\begin{array}{c}\text { Non-trained group } \\
\text { (amateur players) }\end{array}$ & $\begin{array}{c}\text { NHE training group } \\
\text { (professional players) }\end{array}$ \\
\hline Age (years) & $24 \pm 4$ & $24 \pm 5$ \\
Weight $(\mathrm{kg})$ & $61 \pm 4$ & $58 \pm 6$ \\
Height $(\mathrm{m})$ & $1.64 \pm 0.04$ & $1.62 \pm 0.04$ \\
Body mass index $\left(\mathrm{kg} / \mathrm{m}^{2}\right)$ & $22.74 \pm 1.79$ & $22.00 \pm 2.16$ \\
\hline
\end{tabular}

\section{PROCEDURES}

\section{FASCICLE LENGTH EVALUATION}

A B-mode ultrasonography system (DP-30, Mindray Medical International Ltd., Shenzhen, China) with a linear array probe $(53 \mathrm{~mm})$ was used to assess muscle architecture parameters of the $\mathrm{BF}_{\mathrm{LH}}$. All ultrasound scans were taken by an experienced researcher through methods routinely used in our laboratory. ${ }^{24,28}$ The participants were assessed in prone position with the hips neutral, the knees fully extended, and the muscles relaxed. Ultrasound scans were taken at 50\% of the muscle length (i.e., the midportion between the ischial tuberosity and the superior border of the fibular head). The ultrasound probe was positioned perpendicularly to the skin and following the longitudinal axis of the $\mathrm{BF}_{\mathrm{LH}}$, with slight adjustments in probe orientation as necessary to optimize identification of the aponeuroses and fascicles.

Three ultrasound images of each limb were obtained and stored for analysis through the Image software (National Institutes of Health, EUA). Image analysis was performed by an assessor blinded to group allocation. The most visible fascicle in each image was used to estimate the $\mathrm{BF}_{\mathrm{LH}}$ fascicle length using a validated equation. ${ }^{29}$ The average value between the three ultrasound images was used for statistical analyses. Previous data collected in our lab in 20 healthy active men presented acceptable test-retest reliability scores for $\mathrm{BF}_{\mathrm{LH}}$ fascicle length [intraclass correlation coefficient, 0.95 (0.86-0.98); coefficient of variation, 5.5\% (4.-0-9.2); typical error, $0.48 \mathrm{~cm}(0.35-0.79)]$. The nontrained group's data were used to assess the test-retest reliability in female soccer players in the current study.

\section{ECCENTRIC STRENGTH EVALUATION}

The eccentric knee flexor strength during the NHE execution was measured through a custom-made device (Figure 1). This device is similar to the prototype developed by Opar et al. ${ }^{30}$ and has been used in studies with male soccer players. ${ }^{31,32}$ Previous data collected in our lab consisting of 20 healthy active men presented acceptable test-retest reliability scores for knee flexor strength [intraclass correlation coefficient, 0.94 (0.85-0.98), coefficient of variation, 5\% (3.2-6.7\%); typical error, $18.54 \mathrm{~N}$ (13.93-22.36 N)]. The non-trained group's data were used to assess the test-retest reliability in female soccer players in the current study.

Briefly, the participant was positioned to perform the NHE on a platform, and commercially available load cells (E-lastic; E-sporte Soluções Esportivas, Brasilia, Brazil) with simultaneous transference of data via Bluetooth were

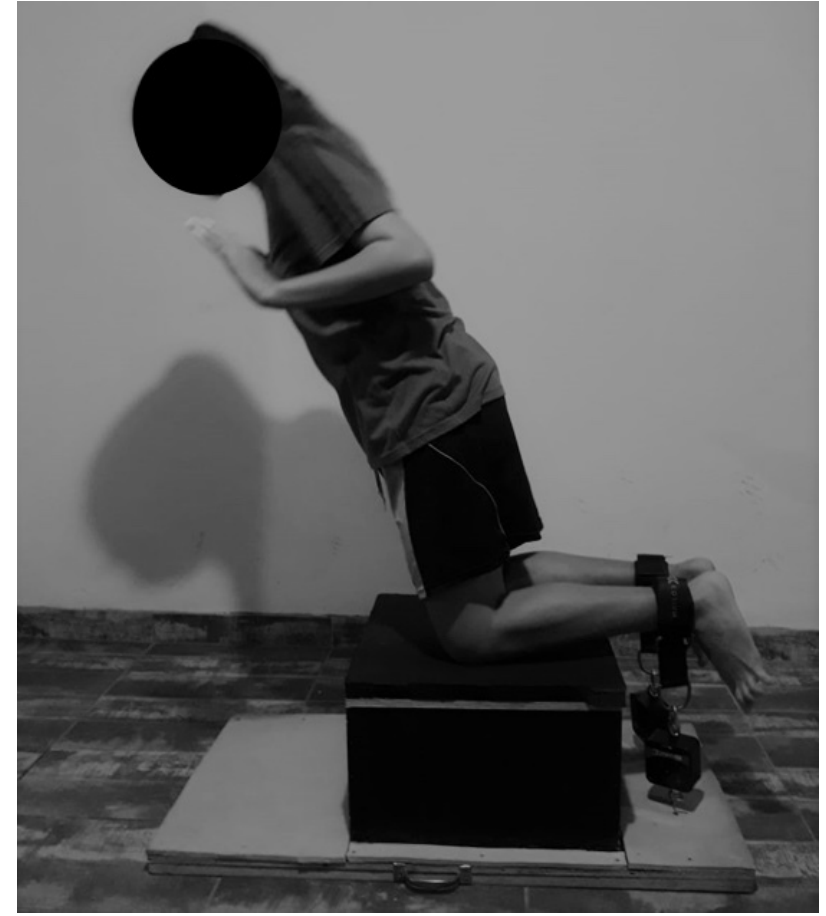
Figure 1: Assessment of eccentric knee flexor
strength during the NHE execution.

fastened around their ankles (right above the lateral malleolus). The participant was instructed to execute the NHE as the following: from the initial position (kneeling, the hip neutral and the torso upright), lay the torso forwards using only the knee joint (e.g., without altering the position of hips or spine), in slow speed and using the hamstring muscle eccentrically during the entire range of motion to avoid the torso acceleration to the floor. The participant should have to use their upper limbs to absorb the fall and to return to the initial NHE position. Each participant performed five NHE repetitions, with a 10 -second rest between attempts. The force values were continuously registered during all repetitions, and the highest force value obtained in each lower limb was considered to statistical analysis.

\section{NHE TRAINING PROGRAM}

The 8-week NHE training program (frequency and number of sets and repetitions) was based on previous studies involving $\mathrm{NHE}^{23,27}$ and provided a progressive workload increase (Figure 2). The NHE training weekly schedule was set by the coaching staff according to the games and travels, al- 


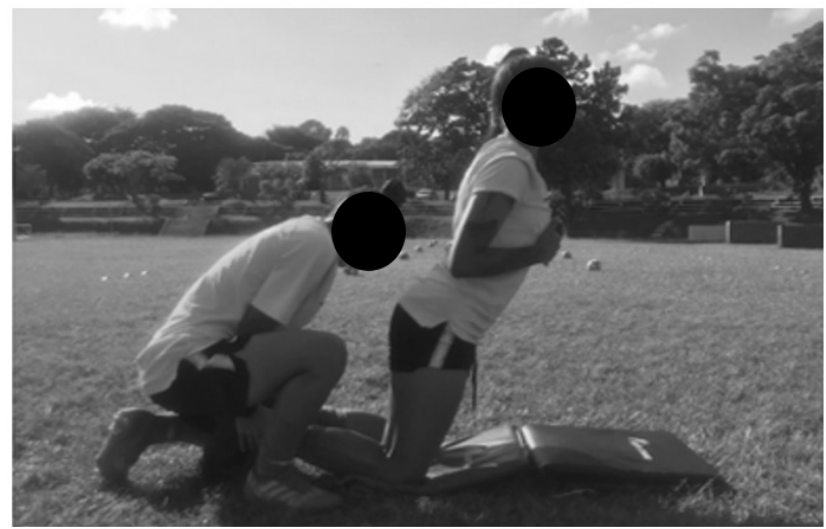

\begin{tabular}{|c|c|c|c|}
\hline Week & Frequency & Sets & Repetitions \\
\hline 1 & 2 & 2 & 6 \\
\hline 2 & 2 & 3 & 6 \\
\hline 3 & 2 & 3 & 8 \\
\hline 4 & 2 & 3 & 10 \\
\hline 5 & 2 & 4 & $8-10$ \\
\hline 6 & 2 & 4 & $8-10$ \\
\hline 7 & 2 & 4 & 10 \\
\hline 8 & 2 & 4 & 10 \\
\hline
\end{tabular}

Figure 2: Left: players performing the Nordic hamstring exercise (NHE); Right: the NHE training program.

ways respecting at least 48 hours between the NHE training sessions. NHE was always performed before soccer practices. A regular warm-up protocol guided by the team strength and conditioning coach was performed before the NHE execution. Players with similar anthropometric characteristics were organized in pairs to perform the NHE. A researcher supervised every NHE session to ensure correct implementation and the training volume (number of sets and number of repetitions per set) as well as proper exercise execution.

\section{STATISTICAL ANALYSIS}

Data collected in non-trained group (amateur players) were used to assess intraclass correlation coefficient (ICC), typical error (TE) and coefficient of variation (CV) of the measures. ICC values were qualitatively recorded as poor $(<0.50)$, moderate $(0.50-0.74)$, good $(0.75-0.90)$, and excellent (>0.90). ${ }^{33}$ Additionally, a CV of $10 \%$ or less was set as the level at which a measure was considered reliable. ${ }^{30}$

In the NHE training group, paired sample $\mathrm{t}$-tests were used to check difference between pre- and post-training in each limb. The significance level was set as $5 \%(\alpha<0.05)$. Effect size (ES) calculation was performed using the Cohen's d. Training effects were considered as "trivial" $(\mathrm{ES}<0.2)$, "small" (ES>0.2), "moderate" (ES>0.5) or "large" (ES>0.8).

The between-limbs average change (pre- to post-training) was used for calculation of individual responsiveness to NHE training. Responders and non-responders were determined using the typical error criteria: non-responders were defined as subjects who failed to achieve an increase that was greater than two times the typical error (TE) of measurement. ${ }^{31}$ Results provided by the non-trained group were used to calculate the TE of measurement. The TE for eccentric knee flexor strength was $12.18 \mathrm{~N}$, thus subjects had to demonstrate at least $24.35 \mathrm{~N}$ of strength gain to be considered responders to the NHE training. The TE for $\mathrm{BF}_{\mathrm{LH}}$ fascicle length was $0.36 \mathrm{~cm}$, thus volunteers had to demonstrate at least $0.72 \mathrm{~cm}$ of fascicle elongation to be considered responders to the NHE training.

\section{RESULTS}

The non-trained group's data demonstrated that the measures used in this study were reliable (Table 2). All participants in the NHE training group attended 16 sessions (i.e., $100 \%$ adherence). The group experienced significant increases $(p<0.05)$ in both lower limbs for the eccentric knee flexor strength (moderate to large effect sizes) and $\mathrm{BF}_{\mathrm{LH}}$ fascicle length (small to moderate effect sizes), as detailed in Table 3 . Twelve players ( $71 \%)$ were considered responders to the training program for the eccentric knee flexor strength, while eight athletes ( $47 \%)$ were responders for the $\mathrm{BF}_{\mathrm{LH}}$ fascicle length (Figure 3). The five non-responders for the eccentric knee flexor strength were also non-responders for the $\mathrm{BF}_{\mathrm{LH}}$ fascicle length.

\section{DISCUSSION}

This is the first study to investigate the effects of a NHE training program on hamstring injury risk factors in professional female soccer players. The main findings were that the NHE training program implemented here increased both the eccentric knee flexor strength and the $\mathrm{BF}_{\mathrm{LH}}$ fascicle length. More than two-thirds of players demonstrated a meaningful increase in eccentric strength, while nearly half achieved consistent fascicle length increases with the NHE training.

Measures of eccentric knee flexor strength have been performed through isokinetic dynamometers for decades, and those devices are considered the gold standard tool for assessing human strength through joint torque measures. A few years ago, Opar et al. ${ }^{30}$ validated a prototype allowing a cheaper and faster assessment of the eccentric knee flexor strength during the NHE execution. While a large cohort study found no clinical value of strength tests with isokinetic dynamometry or the NHE device for predicting risk of hamstring injury, ${ }^{34}$ cohort studies with soccer, ${ }^{12,14-16}$ Australian football, ${ }^{19}$ rugby, ${ }^{18}$ and sprinters ${ }^{17}$ have demonstrated that athletes with eccentric knee flexor weakness are more susceptible to hamstring injury. For this reason, eccentric strength was selected as the primary outcome of the current study, and findings demonstrated that an 8-week NHE training program improved eccentric 
Table 2: Reliability of eccentric knee flexor strength and biceps femoris long head fascicle length measures. Data collected in non-trained group [mean \pm SD (95\%CI)].

\begin{tabular}{lcccccc}
\hline & Measure 1 & Measure 2 & ICC & CV & TE & p-value \\
\hline Eccentric strength $(\mathrm{N})$ & & & & & & \\
$\quad$ Right limb & $235 \pm 35(217-254)$ & $243 \pm 32(227-260)$ & 0.87 & $5 \%$ & $12.74 \mathrm{~N}$ & 0.112 \\
$\quad$ Left limb & $230 \pm 29(215-244)$ & $235 \pm 24(223-248)$ & 0.82 & $5.3 \%$ & $11.97 \mathrm{~N}$ & 0.185 \\
Fascicle length (cm) & & & & & & \\
$\quad$ Right limb & $9.43 \pm 1.86(8.47-10.39)$ & $9.46 \pm 1.71(8.58-10.34)$ & 0.97 & $3.8 \%$ & $0.19 \mathrm{~cm}$ & 0.824 \\
$\quad$ Left limb & $9.78 \pm 1.28(9.12-10.44)$ & $9.93 \pm 1.21(9.31-10.55)$ & 0.92 & $4.2 \%$ & $0.38 \mathrm{~cm}$ & 0.279 \\
\hline
\end{tabular}

$\mathrm{N}$, Newtons, cm, centimeters, ICC, intraclass correlation coefficient; CV, coefficient of variation; TE, typical error.

Table 3: Eccentric knee flexor strength and biceps femoris long head fascicle length of the NHE training group [mean \pm SD (95\%CI)].

\begin{tabular}{|c|c|c|c|c|c|c|}
\hline & Pre-training & Post-training & $\Delta$ & $\Delta \%$ & ES & $\begin{array}{c}\mathrm{p}- \\
\text { value }\end{array}$ \\
\hline \multicolumn{7}{|c|}{$\begin{array}{l}\text { Eccentric strength } \\
\text { (N) }\end{array}$} \\
\hline Right limb & $263 \pm 41(242-284)$ & $298 \pm 48(274-323)$ & 35.31 & 13.41 & $0.82^{C}$ & 0.003 \\
\hline Left limb & $254 \pm 44(231-276)$ & $289 \pm 53(261-316)$ & 34.9 & 13.76 & $0.74^{\mathrm{B}}$ & 0.001 \\
\hline \multicolumn{7}{|c|}{ Fascicle length $(\mathrm{cm})$} \\
\hline Right limb & $\begin{array}{c}9.90 \pm 1.44 \\
(9.16-10.64)\end{array}$ & $\begin{array}{c}10.51 \pm 1.45 \\
(9.76-11.26)\end{array}$ & 0.61 & 6.16 & $0.44^{A}$ & $<0.001$ \\
\hline Left limb & $\begin{array}{c}9.57 \pm 1.09 \\
(9.01-10.13)\end{array}$ & $\begin{array}{c}10.20 \pm 0.89 \\
(9.74-10.66)\end{array}$ & 0.63 & 6.58 & $0.65^{\mathrm{B}}$ & $<0.001$ \\
\hline
\end{tabular}

$\mathrm{N}$, Newtons, cm, centimeters, $\Delta$, mean absolute change; $\Delta \%$, mean percent change; ES, effect size;

A small effect size; ${ }^{B}$ moderate effect size; ${ }^{C}$ large effect size.
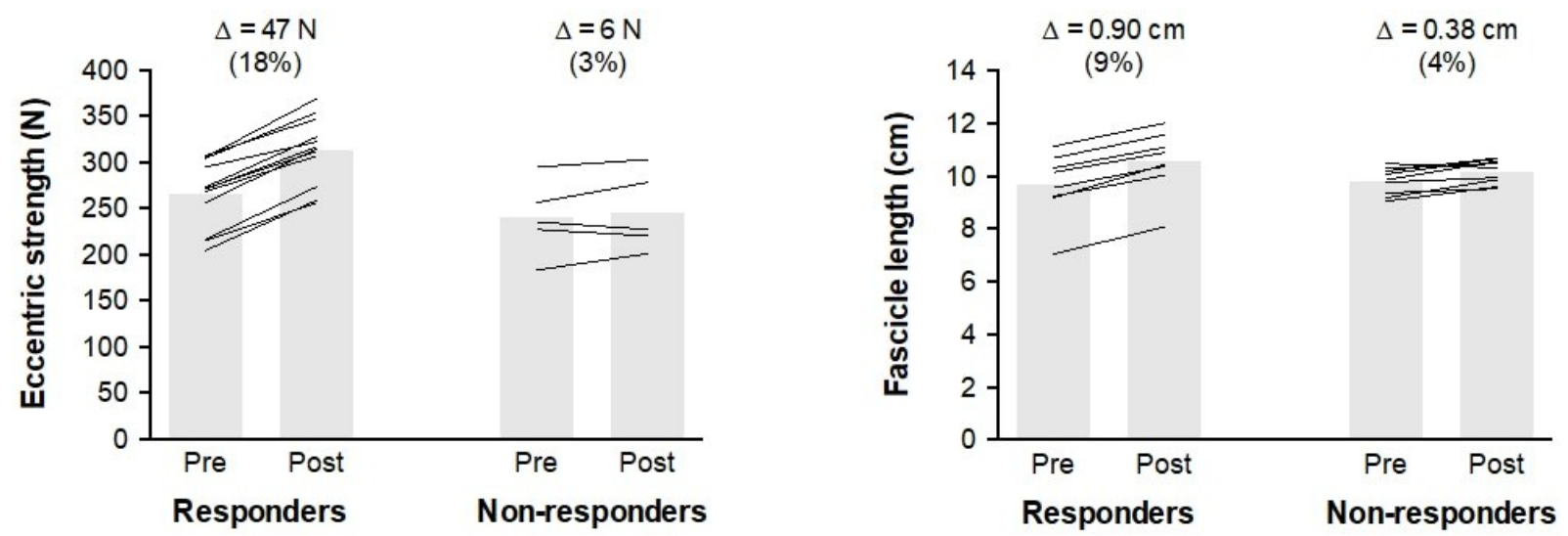

Figure 3: Individual responsiveness to the NHE training program. Black lines indicate individual responses, and vertical grey bars show the group average values. $\Delta=$ absolute and percent changes of responders and non-responders.

strength of the knee flexor muscles of female soccer players.

Professional male soccer players have demonstrated eccentric knee flexor strength values ranging from $\sim 299 \mathrm{~N}$ to $\sim 411 \mathrm{~N}$ during the NHE, ${ }^{34,35}$ while female players in the present study had $\sim 258 \mathrm{~N}$. Previous studies involving 6-10 weeks of NHE training have found increases of $7-11 \%$ on the eccentric knee flexor strength in well-conditioned male athletes. ${ }^{23,27,36,37}$ Therefore, the average increase of $\sim 13 \%$ pre- 
sented by female professional players in the current study suggest a satisfactory response to the NHE training program. It has been suggested that for every $10 \mathrm{~N}$ increase in eccentric knee flexor strength, the risk of hamstring injury can be reduced by $9 \%$ in male soccer players. ${ }^{12}$ Although the same numbers should not be assumed for female players, it is plausible to speculate that the approximate $35 \mathrm{~N}$ increase in eccentric strength found in our study may have aided the prevention of hamstring injury along the season.

A prospective cohort study found that soccer players with shorter $\mathrm{BF}_{\mathrm{LH}}$ fascicles were four times more likely to suffer a subsequent hamstring injury than those with longer fascicles. ${ }^{12}$ The mechanism by which shorter fascicles predispose athletes to injury is not entirely clear, but a reasonable hypothesis suggests that short fascicles (i.e., fewer in series sarcomeres) may be more susceptible to excessive stretching and subsequent injury during eccentric high-intensity contractions, ${ }^{38}$ such as those performed during high-speed running. The fascicle lengthening in response to the NHE training was expected in the present study because it has been consistently reported in both active subjects ${ }^{24}$ and well-conditioned athletes. ${ }^{23,27}$ However, it is curious that female players in the present study increased their $\mathrm{BF}_{\mathrm{LH}}$ fascicle length $(\sim 7 \%$ or $\sim 0.6 \mathrm{~cm})$ with a slightly lower magnitude compared to male athletes submitted to the same training program periodization $(\sim 9-10 \%$ or $\sim 1 \mathrm{~cm}){ }^{23,27}$

The individual responsiveness is an interesting analysis for professionals working in the medical departments and coaching staffs of team sports. Although the average values give us an idea of the team's behavior, it is important to note that individual responses varied. In the present study, $71 \%$ of players had consistent muscle strength gains with the NHE training, which is a similar percentage of responders than those found in male soccer players engaged in a NHE training program during preseason (19 out of 25 players, $76 \%) .{ }^{31}$ Conversely, half of players engaged in the NHE training program in the current study did not experience fascicle length enhancement. All players were engaged in the same soccer training routine and all of them attended every NHE training session, thus adherence issues cannot explain the non-responders. Baseline status also does not seem to explain the training responses, as illustrated by the similar pre-training levels between responders and nonresponders in Figure 3. Interestingly, all non-responders for the eccentric strength were also non-responders for the $\mathrm{BF}_{\mathrm{LH}}$ fascicle length. Further investigation is needed to understand why some athletes respond to NHE training and others do not. In addition, it would be a sports medicine breakthrough if future studies could determine if responders and non-responders have different injury rates during the season.

Like all sport injuries, muscle strains are complex and multifactorial in nature, ${ }^{6}$ and most soccer players present multiple risk factors for sustaining a hamstring injury. ${ }^{28} \mathrm{Ac}$ cording prospective data, ${ }^{12}$ eccentric knee flexor strength and $\mathrm{BF}_{\mathrm{LH}}$ fascicle length account for approximately $30 \%$ of the risk associated with hamstring injury occurrence, thus the other $70 \%$ cannot be undervalued. The posterior chain flexibility, ${ }^{39}$ hamstring-to-quadriceps strength ratios, ${ }^{14,16}$ and proximal neuromuscular control ${ }^{40}$ are examples of modifiable factors also associated with hamstring injury. Therefore, despite the present study focused the effects of a single exercise on only two of those risk factors (eccentric knee flexor strength and $\mathrm{BF}_{\mathrm{LH}}$ fascicle length), a comprehensive approach is recommended for preventive programs. ${ }^{41}$

The current study has limitations. First, this is not a randomized controlled trial. It means that the NHE cannot be assumed as the single factor responsible for changes observed on muscle strength and architecture, despite previous evidence in male players has demonstrated that regular soccer training does not affect the outcomes assessed here. ${ }^{25,36}$ Second, it was not possible to follow the injury rates of the professional players along the subsequent season, which would allow us to verify whether the individual responsiveness to the NHE training program had an influence on the hamstring injuries or not. Third, the number of participants in the current study is small, and caution is recommended regarding the percent distribution of responders and non-responders to the NHE training program. Despite these limitations, this study presents high ecological validity because it was done within the real-world of competitive soccer.

\section{CONCLUSION}

The results of this study indicate that an 8-week NHE training program performed twice a week during preseason increases the eccentric knee flexor strength and the $\mathrm{BF}_{\mathrm{LH}}$ fascicle length in professional female soccer players. The positive effects on two injury risk factors for hamstring strain injury support the adoption of the NHE within a prevention program. Medical and coaching staffs must be attentive and monitor individual responses because not all players benefit from the NHE intervention.

\section{CONFLICTS OF INTEREST}

The authors declare that there is no conflict of interest.

\section{ACKNOWLEDGEMENTS}

BMB thank CNPq-Brazil for the research productivity fellowship.

Submitted: February 17, 2020 CDT, Accepted: July 04, 2020 CDT 


\section{REFERENCES}

1. Ekstrand J, Hägglund M, Waldén M. Injury incidence and injury patterns in professional football: The UEFA injury study. Br J Sports Med. 2011;45(7):553-558. doi:10.1136/bjsm.2009.060582

2. Faude O, Junge A, Kindermann W, Dvorak J. Injuries in female soccer players: A prospective study in the German national league. Am J Sports Med. 2005;33(11):1694-1700. doi:10.1177/03635465052750 11

3. Jacobson I, Tegner Y. Injuries among Swedish female elite football players: A prospective population study. Scand J Med Sci Sports. 2007;17(1):84-91. doi:10.1111/j.1600-0838.2006.0052 $\underline{4 . x}$

4. Tegnander A, Olsen OE, Moholdt TT, Engebretsen L, Bahr R. Injuries in Norwegian female elite soccer: A prospective one-season cohort study. Knee Surg Sports Traumatol Arthr. 2008;16(2):194-198. doi:10.1007/s00 167-007-0403-z

5. Eliakim E, Morgulev E, Lidor R, Meckel Y. Estimation of injury costs: Financial damage of English Premier League teams' underachievement due to injuries. BMJ Open Sport Exerc Med. 2020;6(1):e000675. doi:10.1136/bmjsem-2019-000675

6. Bittencourt NFN, Meeuwisse WH, Mendonça LD, Nettel-Aguirre A, Ocarino JM, Fonseca ST. Complex systems approach for sports injuries: Moving from risk factor identification to injury pattern recognition-narrative review and new concept. $\mathrm{Br} J$ Sports Med. 2016;50(21):1309-1314. doi:10.1136/bjsp orts-2015-095850

7. Coles PA. An injury prevention pyramid for elite sports teams. Br J Sports Med. 2018;52(15):1008-1010. doi:10.1136/bjsports-2016-096697

8. Bahr R, Krosshaug T. Understanding injury mechanisms: A key component of preventing injuries in sport. Br J Sports Med. 2005;39(6):324-329. doi:10.1 136/bjsm.2005.018341

9. McCall A, Carling C, Nedelec M, et al. Risk factors, testing and preventative strategies for non-contact injuries in professional football: Current perceptions and practices of 44 teams from various premier leagues. Br J Sports Med. 2014;48(18):1352-1357. doi:1 $\underline{0.1136 / \text { bjsports-2014-093439 }}$
10. Meurer MC, Silva MF, Baroni BM. Strategies for injury prevention in Brazilian football: Perceptions of physiotherapists and practices of premier league teams. Phys Ther Sport. 2017;28:1-8. doi:10.1016/j.pts p.2017.07.004

11. Opar DA, Williams MD, Shield AJ. Hamstring strain injuries: Factors that lead to injury and reinjury. Sports Med. 2012;42(3):209-226. doi:10.2165/1 1594800-000000000-00000

12. Timmins RG, Bourne MN, Shield AJ, Williams MD, Lorenzen C, Opar DA. Short biceps femoris fascicles and eccentric knee flexor weakness increase the risk of hamstring injury in elite football (soccer): A prospective cohort study. Br J Sports Med. 2016;50(24):1524-1535. doi:10.1136/bjsports-2015-09 $\underline{5362}$

13. Kenneally - Dabrowski CJB, Brown NAT, Lai AKM, Perriman D, Spratford W, Serpell BG. Late swing or early stance? A narrative review of hamstring injury mechanisms during high - speed running. Scand J Med Sci Sports. 2019;29(8):1083-1091. doi:10.1111/sm s.13437

14. Croisier J-L, Ganteaume S, Binet J, Genty M, Ferret J-M. Strength imbalances and prevention of hamstring injury in professional soccer players: A prospective study. Am J Sports Med. 2008;36(8):1469-1475. doi:10.1177/036354650831676 4

15. Fousekis K, Tsepis E, Poulmedis $\mathrm{P}$, Athanasopoulos $\mathrm{S}$, Vagenas $\mathrm{G}$. Intrinsic risk factors of non-contact quadriceps and hamstring strains in soccer: A prospective study of 100 professional players. Br J Sports Med. 2011;45(9):709-714. doi:10.1 136/bjsm.2010.077560

16. Lee JWY, Mok K-M, Chan HCK, Yung PSH, Chan K$M$. Eccentric hamstring strength deficit and poor hamstring-to-quadriceps ratio are risk factors for hamstring strain injury in football: A prospective study of 146 professional players. J Sci Med Sport. 2018;21(8):789-793. doi:10.1016/i.jsams.2017.11.017

17. Sugiura Y, Saito T, Sakuraba K, Sakuma K, Suzuki E. Strength deficits identified with concentric action of the hip extensors and eccentric action of the hamstrings predispose to hamstring injury in elite sprinters. J Orthop Sports Phys Ther. 2008;38(8):457-464. doi:10.2519/jospt.2008.2575 
18. Bourne MN, Opar DA, Williams MD, Shield AJ. Eccentric knee flexor strength and risk of hamstring injuries in Rugby Union: A prospective study. Am J Sports Med. 2015;43(11):2663-2670. doi:10.1177/0363 $\underline{546515599633}$

19. Opar DA, Williams MD, Timmins RG, Hickey J, Duhig SJ, Shield AJ. Eccentric hamstring strength and hamstring injury risk in Australian footballers. Med Sci Sports Exerc. 2015;47(4):857-865. doi:10.1249/ms s.0000000000000465

20. Brockett CL, Morgan DL, Proske U. Human hamstring muscles adapt to eccentric exercise by changing optimum length. Med Sci Sports Exerc. 2001;33(5):783-790. doi:10.1097/00005768-20010500 $\underline{0-00017}$

21. Bizzini M, Dvorak J. FIFA 11+: An effective programme to prevent football injuries in various player groups worldwide-a narrative review. $\mathrm{Br} \mathrm{J}$ Sports Med. 2015;49(9):577-579. doi:10.1136/bjsport s-2015-094765

22. van Dyk N, Behan FP, Whiteley R. Including the Nordic hamstring exercise in injury prevention programmes halves the rate of hamstring injuries: A systematic review and meta-analysis of 8459 athletes. Br J Sports Med. 2019;53(21):1362-1370. doi:10.1136/ bjsports-2018-100045

23. Medeiros TM, Ribeiro-Alvares JB, Fritsch CG, et al. Effect of weekly training frequency with the Nordic hamstring exercise on muscle strain risk factors in football players: A randomized trial. Int J Sports Physiol Perform. 2020;15(7):1026-1033. doi:10.1123/ij spp.2018-0780

24. Ribeiro-Alvares JB, Marques VB, Vaz MA, Baroni $\mathrm{BM}$. Four weeks of Nordic hamstring exercise reduce muscle injury risk factors in young adults. J Strength Cond Res. 2018;32(5):1254-1262. doi:10.1519/jsc.0000 000000001975

25. Lovell R, Knox M, Weston M, Siegler JC, Brennan $S$, Marshall PWM. Hamstring injury prevention in soccer: Before or after training? Scand J Med Sci Sports. 2018;28(2):658-666. doi:10.1111/sms.12925

26. Iga J, Fruer C, Deighan M, Croix MD, James DV. 'Nordic' Hamstrings Exercise - Engagement characteristics and training responses. Int J Sports Med. 2012;33(12):1000-1004. doi:10.1055/s-0032-130 $\underline{4591}$

27. Severo-Silveira L, Dornelles MP, Lima-E-Silva FX, et al. Progressive workload periodization maximizes effects of Nordic hamstring exercise on muscle injury risk factors. J Strength Cond Res. 2018;Publish Ahead of Print. doi:10.1519/jsc.0000000000002849
28. Ribeiro-Alvares JB, Dornelles MP, Fritsch CG, et al. Prevalence of hamstring strain injury risk factors in professional and under-20 male football (soccer) players. J Sport Rehabil. 2020;29(3):339-345. doi:10.11 23/jsr.2018-0084

29. Kellis E, Galanis N, Natsis K, Kapetanos G. Validity of architectural properties of the hamstring muscles: Correlation of ultrasound findings with cadaveric dissection. J Biomech. 2009;42(15):2549-2554. doi:1 0.1016/j.jbiomech.2009.07.011

30. Opar DA, Piatkowski T, Williams MD, Shield AJ. A novel device using the Nordic hamstring exercise to assess eccentric knee flexor strength: A reliability and retrospective injury study. J Orthop Sports Phys Ther. 2013;43(9):636-640. doi:10.2519/jospt.2013.4837

31. de Oliveira NT, Medeiros TM, Vianna KB, Oliveira GS, de Araujo Ribeiro-Alvares JB, Baroni BM. A fourweek training program with the Nordic hamstring exercise during preseason increases eccentric strength of male soccer players. Intl J Sports Phys Ther. 2020;15(4):571-578. doi:10.26603/ijspt2020057 1

32. Ribeiro-Alvares JB, Oliveira GDS, De Lima-E-Silva FX, Baroni BM. Eccentric knee flexor strength of professional football players with and without hamstring injury in the prior season. Eur J Sport Sci. 2020;21(1):131-139. doi:10.1080/17461391.2020.1743 $\underline{766}$

33. Koo TK, Li MY. A guideline of selecting and reporting intraclass correlation coefficients for reliability research. J Chiropr Med. 2016;15(2):155-163. doi:10.1016/i.jcm.2016.02.012

34. van Dyk N, Bahr R, Burnett AF, et al. A comprehensive strength testing protocol offers no clinical value in predicting risk of hamstring injury: A prospective cohort study of 413 professional football players. Br J Sports Med. 2017;51(23):1695-1702. doi:1 $\underline{0.1136 / \text { bjsports-2017-097754 }}$

35. Buchheit M, Cholley Y, Nagel M, Poulos N. The effect of body mass on eccentric knee-flexor strength assessed with an instrumented Nordic hamstring device (Nordbord) in football players. Int J Sports Physiol Perform. 2016;11(6):721-726. doi:10.1123/ijsp p.2015-0513

36. Mjølsnes R, Arnason A, Østhagen T, Raastad T, Bahr R. A 10-week randomized trial comparing eccentric vs. concentric hamstring strength training in well-trained soccer players. Scand J Med Sci Sports. 2004;14(5):311-317. doi:10.1046/i.1600-0838.2003.36 7.x 
37. Lacome M, Avrillon S, Cholley Y, Simpson BM, Guilhem G, Buchheit M. Hamstring eccentric strengthening program: Does training volume matter? Int J Sports Physiol Perform. 2020;15(1):81-90. doi:10.1123/ijspp.2018-0947

38. Morgan DL. New insights into the behavior of muscle during active lengthening. Biophys $J$. 1990;57(2):209-221. doi:10.1016/s0006-3495(90)8252 $\underline{4-8}$

39. Witvrouw E, Danneels L, Asselman P, D’Have T, Cambier D. Muscle flexibility as a risk factor for developing muscle injuries in male professional soccer players. A prospective study. Am J Sports Med. 2003;31(1):41-46. doi:10.1177/0363546503031001180 1
40. Schuermans J, Danneels L, Van Tiggelen D, Palmans T, Witvrouw E. Proximal neuromuscular control protects against hamstring injuries in male soccer players: A prospective study with electromyography time-series analysis during maximal sprinting. Am J Sports Med. 2017;45(6):1315-1325. doi:10.1177/036354651668775 $\underline{0}$

41. Buckthorpe M, Wright S, Bruce-Low S, et al. Recommendations for hamstring injury prevention in elite football: Translating research into practice. $\mathrm{Br} \mathrm{J}$ Sports Med. 2019;53(7):449-456. doi:10.1136/bjsport $\underline{\mathrm{s}-2018-099616}$ 